that showed intolerance to intermal medication or inunctions, readily tolerated the injections. A case of multiple cutaneous gummata, in a physician, following a long-standing extragenital infection, responded promptly to six ill-tolerated injections, after inunctions. internal administrations and potassium jodid in large doses had failed to favorably influence the condition. A case of severe syphilis, associated with progressive gummatous infiltrations and destruction of tissue, yielded promptly and completely to one course of injections, and after other methods and large doses of potassium iodid failed to benefit. Clinical examples of this character could be multiplied almost indefinitely, but it will suffice to state that, in point of efficacy, the treatment embraces all that is desirable, and that patients experience marked improvement, not only during the treatment, but a state of well-being that persists for many months after the treatment is suspended. In the vast majority of cases the patients show the greatest tolerane: in a few, owing to inexplicable idiosyncrasy, the distress is severe enough to render the treatment uncomfortable or a change to some other form highly desirable if not imperative. Taken all in all, its greater tolerance and the absence of complications should give this formula the preference over other forms of injections, and with the improvement in these directions the other natural advantages which accrue to the injection treatment over the internal and innunction methols. should give it the high and important place in syphilitic therapy which my personal experience during the past twelve months leads me to firmly believe it justly and deservedly holds. It has not, however, reached as yet that high state of perfection which bids it to entirely supplant all other forms; both the internal and inunction nethods will still play very important rôles, not only as separate forms, but also when combined with each other or with injections, in accordance with the special indications. Every modification which renders the injections more tolerable and. at the same time, removes the likelihood of complications, is a step nearer the goal, and, inasmuch as the obstacles leading thereto are almost purely technical, it seems not at all unlikely that this goal can and will be reached as soon as mercurial injections attain the same relative tolerance that jodin injections have recently attained in iodopin.

One word of caution should be sounded in the use of this preparation: It is best to begin the treatment with a minimum dose ( $1 / 4$ to $1 / 2$ grain per injection) and to gradually increase to 1 crain or more, in acendance with the degree of tolerance manifested by the patient. Great care should be exercised that the technic is properly carried out, and that a syringe, provided with a retaining screw, is cmployed; the screw should be properly set to guard against an excessive dose. These features should be forcibly impressed because their inadvertence in the hands of a few colleagues has been followed by untoward results. In one unfortunate instance an injection was made into the calf of the leg, instead of utilizing the gluteal region.

To recapitulate, the success of syphilitic therapy depends on the amount of mercury assimilated by the body. no matter in what form or through what avenue it is administered. Inunctions are objectionable because they are uncleanly, court comment and publicity, entail inexact dosage and predispose to dermatitis. The internal treatment is inaccurate, predisposes to gastro-intestinal disturbances, emaciation, anemia and the assimilated mercury is subjected to the altering, filtering and eliminating action of the liver. The injection method dispenses with all the above objections and combines with rapidity of action, relative greater efficacr, shorter treatment, diminished recurrences. Its strongest objections, in all its various forms, have been intoleranee (local, pain and induration), grave complications and small and too oftrepeated dosage, instability, difficult preparation and administration of the remedy. These objections have been in a measure relieved by the above modified formula of oleum cinereum.

iblibigrapin:

1. Alex. Wood: Ziemssen, Handbuch, d. Algemeinen Therapie, 1880 .

2. Chas. Hunter and Barclay Hill: London Lancet, 1856 1864 .

4. Scarenzio: Annali Universali, 602, 1865.

5. Lewin: Annal. d. Charite, xiv, 1868 .

6. Welander: Archir \&. Dermatologie u. Syph., 46

7. Blaschko: Arelin, Klin. Woch. 46 , November, 1868

8. Lewin: Ibid.

9. Lewin: Ibid.

10. Zeissl: 1870, Lehrbuch d. Syph., ist5, p. 376.

11. Lewin: Berlin Klin. Woch., 1876.

12. Lang: Lehrbuch d. Syphilis, 1890 .

13. Ullmann: Wien Med Blätter, 1889

14. Lang: Wien. Med. Wochenschi. 1889.

15. Düring: Monatsheft. f. Prak. Derm., ix. p. 490

15. Düring: Monatsheft. f. Prak. Delm., ix, p.
16. R. W. Taylor: Med. News, December, 1889 :

17. Watrazewski : Arch. f. Dermat. u. Syph., 46, 21

18. Lesser : Deut. Med. Woch., 1894, 39

19. Bayet: Jour. des Malad. Cutan. et Syph., 1895.

20. White, J. C.: The present status of hypodermic therapy of syphilis, 1894 .

29 West Seventh Street.

\section{TREATMENT OF TUBERCULAR PERITONITIS.} WITH 'THE REPORT OF A CNIQUE CASE.*

MILES F. PORTER, A.M., M.D.

Professor of Surgery and Clinical Surgery. Fort Wayne College of Medicine.

FOR'T WAYNE, IND.

The opinions advanced in this paper are based on a study of the literature of the subject and a personal experience in the operative treatment of twelve cases. The time and the occasion make it incumbent on me to express myself concisely. No attempt, therefore, is made to explain in detail the reasoning nor the observations on which the opinions are based.

\section{VARIOUS CURATIVE AGENCIES.}

All forms of tuberculous peritonitis have been known to recover under medical treatment alone. All recoveries from tuberculosis of the peritoneum which follow operation can not be said to be clue to the operation. The percentage of cures following operation is probably not so high as one is led to believe by the statistics of operators. The mortality of operation per se is not underestimated.

Celiotomy has a decidedlv curative effect. This effect is due, not to any single cause, but to several. There is good reason for believing that all the theories offered are founded upon facts, but no single theory will explain all the cures.

\section{LIGHT AS A CURATIVE IGENT.}

The importance of the curative effect of light and air are, I believe, underestimated by most authors. Generally speaking, the best results have followed those operations in which the peritoneum was freely exposed both to light and air. All forms of the disease have been cured by operation, although the ascitic form has yielded the best results and the ulcerating and caseating forms the worst. Other foci are benefited by operation, so that

* Read at the Fifty-third Annual Meeting of the American Medical Association, in the Section on Surgery and Anatomy. and approved for publication by the Executive Committee: Drs. H. 0 . Walker, A. J. Ochsner and DeForest Willard. 
the existence of tubercular deposits, in the lung, for instance, adds another reason for operation in a given case, rather than against it.

\section{OPERATIVE TECHNIC.}

The operative technic in tubercular peritonitis should be such as to give the patient the benefit of as nearly all of the known curative agencies as is possible with the use of good judgment. The inoculation of a tuberculous peritoneum with putrefactive bacteria is a procedure too dangerous to be practical. Incision should be free; fluid, if present, completely removed; tubercular foci, if accessible and not too numerous, should be remored. Adhesions should not be disturbed save when necessary for the removal of tubercular deposits, fluid or the relief of bowel obstruction. An exception to this rule should be made in those cases in which the adhesions are easily separated and extensive enough to prevent free access of light and air. Drainage is dangerous and should not be used except in cases of mixed infection. Lavage with hot water is not injurious and may be beneficial. Chemical antiseptics should not be used ve in mixed infections. The abdominal cavity should be freely exposed to light and air for several (ten to fifteen) minutes. I can conceive of no valid objection to the exposure of the cavity either to the $x$-rays or the ultra-violet rays of Finsen. I would advise a trial of both of these agents, and am preparing to use the latter in the next case coming to me for treatment. That actinic light will penetrate the human body seems proven, but there seems to be sufficient reason for believing that the efficiency both of the $x$-rays and actinic light, in the treatment of tubercular lesions, is much enhanced by exposure of the lesion to the direct influence of the rays.

There is good reason for believing that operative treatment along the lines indicated above, coupled with direct exposure of the abdominal cavity and contents to actinic light, or to the $x$-rays, will prove a better method of treatment for tubercular peritonitis than any other yet devised. In case the actinic light or the $x$-rays is not available, the cavity and contents should be freely exposed, for several minutes, to the strongest light that is nvailable.

\section{REPORT OF A UNIQUE CASE.}

The following case is deemed worthy of record. A synopsis is: Tubercular ascitic peritonitis of lower abdomen and pelvis; protrusion (hernia) of sac through inguinal canal; excision of sac; closure of canal; median laparotomy with complete removal of fluid; cure of hernia and tubercular peritonitis.

GASE 1.-McD., female, aged 14, an inmate of the Orphans' Home, was referred to me by Dr. L. P. Drayer, for an operation for radical cure of hernia. An examination showed a reducible, right inguinal hernia, with a suspicious dulness and hardness of the lower abdomen. Family history negative. Had been an inmate of the home three years. In November, 1900, complained of lump in right groin and some feeling of distress at this point, as well as in whole lower abdomen.

Operation.-In April, 1901, she was placed in my care at the Hope Hospital. After the usual preparation, the operation was done under ether anesthesia. An incision was first made down to the sac, when it occurred to me that the case might be one of hernia of the bladder. A solution of permanganate of potash was therefore thrown into the bladder and a hypodermic syringeful of fluid subsequently withdrawn from the hernial sac. This fluid showing no traces of the permanganate proved this suspicion incorrect and an incision was made into the sac large enough to permit introduction of the finger. I now learned that I had a large cavity filled with fluid and of uncertain origin. I therefore opened the belly in the median line for a distance of three inches between the umbilicus and pubes and through this incision discovered for the first time the true nature of the trouble. The peritoneum forming the sac was studded with tubercles. The roof of the sac was formed by agglutinated intestines and stretched across the abdomen, about on a level with the iliac crests. The pelvic contents were healthy save that the peritoneum covering them was studded with tubercles. The cavity was emptied of fluid, wiped dry, the hernial sac excised and both wounds closed with catgut sutures, including the skin. The patient's recovery was uneventful and she is now (eleven months after the operation) enjoying apparently perfect nealth.

It is proper to note here that after leaving the hospital, she was treated by Dr. Drayer, her physician, for two months by abdominal inunctions of Credê's ointment and the internal administration of hypophosphites, and was given the full benefit of the sunshine and open air.

Thomson ${ }^{16}$ has had three cases in male children in which there was tuberculosis of the patent vaginal process coexistent with general peritoneal tuberculosis. The cases were cured either by simple incision of the process or by excision of it. Gould also savs Harold Stiles, Goldman and others have reported similar cases. I have not been able to find the reports of Stiles or Goldman. $J_{o r d a n}{ }^{75}$ reports a case of tuberculosis sicca of a large irreducible inguinal hernia. After an exploratory incision, the hernia became reducible, the patient's health improved and the thick masses found at the time of the operation largely disappeared, but a sinus which discharged thin pus still remained. Naumann ${ }^{44}$ reports two cases of congenital hernia with peritoneal tuberculosis in which he withdrew the fluid through the hernial opening. Further details of Naumann's cases are not given in the abstract referred to and the original $^{76}$ article was not available when this was written.

These are all the cases similar to mine of which I could find the reports. It will be noted that mine is unique in that the hernia was acquired and consisted only of sac and fluid contents.

\section{BIBLIOGIAPIIY.}

1. Tait et al. : Annual of Universal Med. Sci., 1888, vol. i, p. 372. E. 2. Pribram et al. : Annual of Universal Med. Sci., 1889, vol. ii,

E., 57. Feetley et al. : Annual of Universal Med. Sci., 1889, vol. iii,
B., 16. 4. Osler et al. : Annual of Universal Med. Sc1., 1891, vol. il, F., 49, et seq. ii, C., 44, et seq. iii, C., 33 , et seq. . Annual of Universal Med. Sci., 1894, vol. I, I., 73. Taylor et al.: Annual of Universal Med. Sci., 1894, vol. i, D.,
8. Roersch et al. : Annual of Universal Med. Sci., 1894, vol. ili, C., 32, et seq.

C., 32 , Folct et al. : Annual of Universal Med. Sci, 1896, vol. i, D., 63. Morris et al. : Annual of Universal Med. Sci., 1896, vol. ili, C., 92 . Kichardière et al. : Annual of Universal Med. Sci., 1895, vol. i, 11. Kicha 73 .

12. 'Treves et al. : Annual of Universal Sci., 1895, vol. 111, C., 20. 13. Greig Smith: Abdominal Surgery, vol. ii p if

14. Whittaker : The Cincinnati Lancet and Clinic, vol. viii, p. 357. 15. Sajous : Cyclopedia, vol. $v$, p. 432 .

16. Tajous : Cyclopedia, vol. v, p. 432 .

17. 'Tyson: Practice of Medicine, p. 383 .

18. MeDonald : Surgical Diagncsis, p. 286

19. Neff: Southern Surgery and Gynec. Trans., vol. xiii, p. 377.

20. Neff: American Text-Book of Surgery, p. 756 .
21. Dennis : System of Surgery, vol. Iv, p. 357 .

22. König: JoUrNAL A. M. A., vol. xv., p. 827 .

23. Terrillon : JournaL A. M., A., vol. xv, p. 874.

24. Shoemaker : JounNaL A. M. Ä., vol. xil, p. 641

25. John (x. Clark : Progressive Medicine, June, 1899, p. 187.

26. Jacobson: Medical News, vol. Ixvi, p. 253 .

27. Nolen : Medical News, vol. Ixili, p. 412.

28. Deaver : Medical News, vol. Ix, p. 316.

30. Alexandrofi: Medical News, vol. lix, p. 48

31. Spaeth: Medical News, vol. Ivi, p. 150.

32. Czerny: Medical News, vol. lvil, p. 20

33. Albert: Medical News, vol. liv, p. 603

34. Spath: Medical News, vol. liv, p. 681 .

35. Pribram: Medical News, vol. ilf, p. 435.

36. Trzebicky : Medical News, vol. liti, p. 46

7. Trzebicky : Cincinnati Lancet and Cínic, vol. xi, p. 424

39. Poten: Medical Record, vol. xxxi, p. 635. 


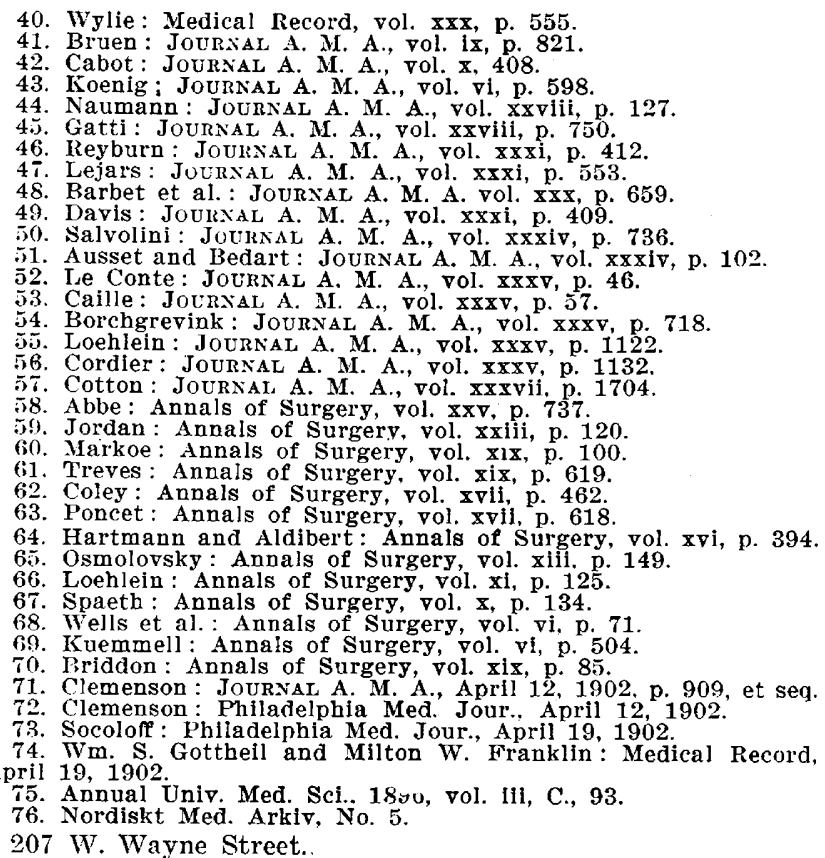

207 W. Wayne Street.

\section{DISCUSSION}

Dr. Joseph Ransonoff, Cincinnati-It is very evident that no one method is going to be of advantage in all cases, and also that very many eases of so-called surgical tuberculosis get well under medical treatment. It is perhaps an inopportune time to discuss this subject, so far as the surgical aspects are concerned, but it seems that the time is not far distant when the $x$-ray will be enabled to make a surgical operation superfluous in some cases. In cases which have apparently gotten well and in which relapses made second operations necessary, where the $x$-ray had been used in the meantime, such a change had taken place in the tubercular nodules as to make one feel some remarkable good was accomplished by the $x$-ray. In two of my cases of ascites I did nothing but drain. Both recovered perfectly, and both young women are now in good health. One of these cases is of 7 years' standing. I did not go to the radical procedure of removing the tubes, although it has been said that it is just as well to do so, in order to prerent tuberular progeny. We have all seen tuberculosis of the male gland treated simply by incision and in whom subsequently the possibility of enjoying parentage was not interfered with. Are we justified in coming to the conclusion that a tubercular tube must be removed any more than a tubercular testicle should be? Conservatism is the order of the day in one and why not in the other. In these cases it has been my experience that the less the interference the better and we should not interfere unless we have to. The danger of postoperative generalization of the disease must not be overlooked.

Dr. A. E. Halsten, Chicago-My experience in the operative treatment of tubercular peritonitis is limited to eight cases. One of these cases demonstrates that operative treatment is not always successful, and that it is not, as is generally supposed, devoid of danger. This patient died as the immediate result of operation. A second case demonstrates that complete recovery is possible, even where there is extensive glandular involvement.

My opinion is that light and air have very little effect on this condition. It is difficult for me to see how such short exposure of the peritoneum to the air and light could affect materially well-developed tubercles. $\mathrm{My}$ experience in this disease leads me to believe that the good effect of the operation is due entirely to the reaction that follows the trauma to which the peritoneum is subjected. Gatti demonstrated in his experimental work on tuberculosis of the abdomen, that the disappearance of the tubercles and cicatrization which resulted after operations for tubercular peritonitis, was the result of the bactericidal action of the exudate that followed opening of the peritoneal carity. He further found that this exudate which corresponded in its chemical properties to blood serum possessed a greater bactericidal action than does normal blood serum. From this, it is my opinion that the operation will be followed more frequently by cure if we resort to swabbing and irrigating the peritoneal cavity. I do not believe that any chemical substance that can be used with safety in the peritoneal cavity is of much value in the cure of peritoneal tuberculosis. Undoubtedly the good effects that have followed the use of iodoform are due to its action in producing traumatic peritonitis. As to the breaking up of adhesions, I have found that it can not be done with safety to the patient. In these cases, where the adhesions are very extensive, it is better to limit the operation to the opening of the peritoneal cavity to evacuating the fluid and swabbing the surface of the diseased membrane with salt solution. In cases where we have a number of circumscribed, sacculated exudates, I consider that each of these cavities should be opened and drained. I am not in favor of immediately closing the abdomen in these cases, but believe that considerable benefit follows drainage.

As to the etiology, we now know that by far the greatest number are from infection that spreads from the pleura, or lung, and that it is only in rare cases that the primary focus can be demonstrated in the tubes. We must also remember that where the tubes are found diseased that this condition may be secondary to the abdominal tuberculosis.

As to the prognosis after operative treatment, it may be said that the best results are to be had in those cases with the ascitic form of tuberculosis. In these, a definitive recovery may be expected in from 40 to 50 per cent. In the adhesive form, the prognosis is very much more unfavorable, only about 10 or 20 per cent. recovering after operation. In the ulcerative and suppurative form, operation is, in my opinion, practically useless. As to the value of removing the tubes in these cases, I believe that it will be difficult to determine in any case positively whether or not the tubes are the primary seat of disease. If for any reason we suspect they are, it would be only rational to remove the tubes at the time of operation.

I wish to report two cases that are of peculiar interest, inasmuch as one illustrates a complete cure, and another a fatal termination:

CASE 1.-Miss D. Young woman, unmarried, aged 19, had up to two weeks before been well. At that time she noticed that the abdomen was larger than usual. This rapidly increased and was associated with indefinite abdominal pain and obstinate constipation. There was some dysuria and a decided diminution in the quantity of urine. On examination the abdomen was found considerably distended and there was free fluid in the abdominal cavity. The thorax was negative, as were the liver and pelvic organs. There was no definite abdominal tumor and the general appearance was fairly good. The skin was decidedly pigmented, so that it had a bronzed appearance which suggested Addison's disease. The selera was icteric.

There was a slight puriform vaginal discharge which on examination showed no tubercle bacilli or gonococci. At the end of the week she was operated on.

A second examination before operation showed an area of dulness which extended from a point half-way between the ensiform cartilage and the umbilicus and pubis. This area was wider in the meso-gastrium than above and below, measuring at its widest part about four inches. On palpation there could be felt a distinct tumor mass, spindle-shaped in outline and giving the sensation of fluctuation. This was freely movable latterly, but appeared attached above and below. On each side of this dull area there was a tympanitic area on percussion, until the area of free abdominal fluid was reached. A diagnosis of abdominal tuberculosis was made by excluding other forms of ascites. There was no history of tuberculosis in the family.

operation.-The abdomen was opened by a median incision, and a large quantity of straw-colored fluid escaped. The intestines were found adherent in many places; it was closely studded throughout its entire extent with small miliary tubercles. The bursa omentalis was rolled on itself and in its lumen was fluid. The lower end of the omental tube was attached 
to the anterior abdominal wall close to the pubis. No at tempt was made to separate the inherent coils of intestine. The Huid was evacuated as completely as possible and then drained.

The patient's condition during the first twenty-four hours following operation was not materially changed; temperature normal, pulse rapid and mind clear. At the end of the first twenty-four hours she was suddenly attacked with severe epistaxis. This was controlled by plugging the nares. Within a few hours hemorrhages began from all the mucous membranes. At the same time large purpuric spots appeared on the chest and the extremities, which increased in size and number until the entire surface of the body was covered. Intermuscular hematoma also developed. The temperature rose to 100 F., pulse gradually became imperceptible and she died in coma thirty-six hours after the operation.

(Discussion continued on p. 624.)

\section{FURTHER EXPERIENCES WITH A MODIFICA- TION IN THE OPERATIVE METHOD FOR \\ INVETERATE RELAPSING AND ALL AGGRAVATED FORMS OF PES EQUINO-VARUS.* \\ A. F. JONAS, M.D.}

Professor of Surgery in the Medical Department of Nebraska Unirersity ; Surgeon to the Omaha (M. E.) Hospital, the Douglas County and Wise Memorial Hospitals; Chief Surgeon of the Union Pacific Railroad Company. OMAHA.

Congenital deformities involving chiefly the mediotarsal joint come so frequently to our notice that they seem to have lost interest. Manipulations, brisement forcé, tenotomies and retentive appliances when carried out with judgment and patience in time tend to recovery in a large number of cases. When these corrected deformities pass from under the observation of the surgeon the results are designated as satisfactory, meaning by that. that the plantar surface rests squarely on the fioor and that walking is accomplished, not perfectly, for there is still a slight limp, a slight toeing inwards, possibly a moderate rolling inwards of the entire extremity. The patient and friends are cautioned that relapse is possible and probable if corrective measures are at once abandoned. Your injunction, it is one thing to correct a deformity and an entirely different and more important matter to keep it corrected, is given with emphasis in the hope that it will be heeded. It is a well-known fact that individuals often tire of prolonged attention and care so needful to make permanent a certain result. Consequently, many cases recorded as cured return after a lapse of time, partly or completely relapsed. Often the deformity has become aggravated to an extreme degree, so that the outer and upper side of the foot is the surface bearing the superimposed weight, the plantar surface pointing inward and backward, presenting a well-known type known as inveterate and relapsed talipes equino-varus. Every surgeon is brought face to face with relapsed cases of his own, he sees more who have been in the hands of other surgeons. It is impossible to repress the desire for some method that promises greater certainty as to permanency. He has found that gradual corrective measures, or operative procedures that involve a long post-operative treatment are unsatisfactory, chiefly on account of indifference on the part of the patient or his attendants. Constant attention is necessary; retentive apparatus is early broken or is rapidly outgrown, requiring frequent renewal, creating

* Read at the Fifty-third Annual Meeting of the American Medical Association, in the Section on Surgery and Anatomy, and approved for publication by the Executive Committee: Drs. $\mathbf{H}$. O. walker, A. J. Ochsner and DeForest Willard. an expense unwillingly borne. Unfortunately, the vast number of cases of foot deformity are found among the poor, who can ill afford the necessary appliances. They have not the means nor the time to devote to the proper attention demanded $\mathrm{ky}$ such a case. The indications are plain. Some plan must be devised whereby a pes equino-varus may be corrected which is mnattended by a prolonged after-treatment.

NATURF OF THE DEFORMITY I NDEI CONSIDERATION.

The deformity that shall engage our attention for a few moments consists of a deviation inward and downward of that portion of the foot chiefly anterior to the medio-tarsal joint, causing the superincumbent weight to be borne on the outer and often the dorsal side of the foot, with a shortening of all the soft structures on the concave side of the deformity, consisting of the skin, superficial and deep fascia, fibers of the internal tasciculus of the plantar fascia, the adductor hallucis muscle, internal plantar nerve and artery, the tendon of the tibialis posticus and anticus, internal lateral and calcaneo-scaphoid ligaments. The soft structures on the outer or convex side of the deformity are elongated. The tarsal bones have become modified in accordance with their abnormal relations to each other.

HOW HIIE DEFORMITY MAY BE OVERCOME.

The indications to be met consist in elongating the shortened soft structures, replacing the bones, dividing and excising on the convex side of the deformity such hypertrophied and distorted osseous structures as interfere with complete replacement. Whether this is accomplished by force or by subcutaneous or open-cut. ting operation the tendency to recurrence must alwayg be taken into accoun, therefore, over-correction has become the rule. And yet this over-correction has not always been sufficient to prevent recurrence. All operative and mechanical methods require repeated sittings, extending over a considerable period of time, making it irksome to the patient, and he frequently passes from obserration before the cure is complete.

$$
\text { TILE PFELPS OPERATION. }
$$

Phelps, in 1881, made the most radical departure from the then prevailing methods, by boldly cutting all the soft structures on the concave side of the deformity and then forcing the foot into a valgus position. His earlier efforts were followed by partial recurrence of the deformity owing to imperfect antisepsis.

When Schede made known his observations on healing under a moist blood-clot in bone cavities, its application found a place in the Phelps operation. The wound was covered with a silk protective, retaining a blood-clot under it, insuring a more rapid reparative process and a less degree of recurrence. Many modifications of the Phelps method have been undertaken, chiefly by Mr. Arbuthnot Lane, F. H. Kellock and Muirhead Little, with the aim to cover the large wound, and Dr. William Gardner sought to overcome the osseous defects by inserting between the scaphoid and astragalus a wedge of decalcified bone to fill the space resulting from correcting a severe varus deformity.

\section{TIE AUTHOR'S MEFHOD.}

It was the writer's privilege to present to the Westerm Surgical and Gynecological Association at its Omaha meeting, a modification which has proven useful in the hands of several surgeons, in permitting immediate correction of the deformity and at the same time guarding against recurrence. The steps leading to the adoption of the plan were made after personal trials of various skin-flap operations, both pedunculated and free. 'They 